\title{
BROOKHFVEN
}

NATIONAL LABORATORY

BNL-75346-2006-CP

\section{RHIC Upgrades for Heavy Ions and Polarized Protons}

\author{
W. Fischer, J. Alessi, I. Ben-Zvi, V. Litvinenko, T. Roser
}

Presented at the 2005 Particles and Nuclei International Conference

(PANIC 2005)

Santa Fe, NEW MEXICO

October 24-28, 2005

\author{
Collider - Accelerator Department \\ Brookhaven National Laboratory \\ P.O. Box 5000 \\ Upton, NY 11973-5000 \\ www.bnl.gov
}

Notice: This manuscript has been authored by employees of Brookhaven Science Associates, LLC under Contract No. DE-AC02-98CH10886 with the U.S. Department of Energy. The publisher by accepting the manuscript for publication acknowledges that the United States Government retains a non-exclusive, paid-up, irrevocable, world-wide license to publish or reproduce the published form of this manuscript, or allow others to do so, for United States Government purposes. 


\section{DISCLAIMER}

This report was prepared as an account of work sponsored by an agency of the United States Government. Neither the United States Government nor any agency thereof, nor any of their employees, nor any of their contractors, subcontractors, or their employees, makes any warranty, express or implied, or assumes any legal liability or responsibility for the accuracy, completeness, or any third party's use or the results of such use of any information, apparatus, product, or process disclosed, or represents that its use would not infringe privately owned rights. Reference herein to any specific commercial product, process, or service by trade name, trademark, manufacturer, or otherwise, does not necessarily constitute or imply its endorsement, recommendation, or favoring by the United States Government or any agency thereof or its contractors or subcontractors. The views and opinions of authors expressed herein do not necessarily state or reflect those of the United States Government or any agency thereof. 


\title{
RHIC upgrades for heavy ions and polarized protons
}

\author{
W. Fischer, J. Alessi, I. Ben-Zvi, V. Litvinenko and T. Roser \\ Brookhaven National Laboratory, Upton, New York, USA
}

\begin{abstract}
The Relativistic Heavy Ion Collider (RHIC), in operation since 2000, has exceeded its design parameters. The Enhanced Design parameters, expected to be reached in 2009, call for a 4-fold increase over the heavy ion design luminosity, and a 15-fold increase over the proton design luminosity, the latter with an average polarization of $70 \%$. Also in 2009 , it is planned to commission a new Electron Beam Ion Source, offering increased reliability and ion species that cannot be supplied currently. The upgrade to RHIC II, based on electron cooling of the beams, aims to increase the average heavy ion luminosity by an order of magnitude, and the polarized proton luminosity by a factor 2-5. Plans for an electron-ion collider eRHIC is covered in another article in these proceedings.
\end{abstract}

Keywords: Heavy ions, Polarized protons, Collider

PACS: $29.20 . \mathrm{Dh} ; 29.27 .-1$

\section{INTRODUCTION}

The Relativistic Heavy Ion Collider (RHIC) at Brookhaven National Laboratory was commissioned in 2000. It is currently the only collider of heavy ions, and the only collider of polarized protons. Since 2000 the heavy ion luminosity has increased by 2 orders of magnitude (Fig. 1), and now exceeds the design values (Tab. 1). Four different ion combinations collided $\left(\mathrm{Au}^{79+}\right.$ on $\mathrm{Au}^{79+}, \mathrm{d}^{+}$on $\mathrm{Au}^{79+}, \mathrm{Cu}^{29+}$ on $\mathrm{Cu}^{29+}$, and polarized $\mathrm{p}^{+}$on polarized $\mathrm{p}^{+}$on), including one asymmetric combination, at a total of 7 different center-of-mass energies (from $19.6 \mathrm{GeV} / \mathrm{n}$ to $409.8 \mathrm{GeV}$ ). The average polarization of stored proton beams reached $46 \%$, and allowed for the first long physics run in 2005. Proton beams can be delivered with transverse and longitudinal polarization. In the most recent polarized proton run, $56 \%$ of the calendar time was spend in physics stores. Luminosity was delivered to 2 high-luminosity experiments (PHENIX and STAR), and three more experiments (BRAHMS, PHOBOS, and PP2PP).

The planned RHIC upgrades target higher luminosity and proton polarization, as well as increased operational flexibility and reliability. Here we will discuss the evolution towards the Enhanced Design parameters, the new Electron Beam Ion Source (EBIS), and RHIC II, a luminosity upgrade based on electron cooling. A number of other upgrades are planned or under investigation. These include reliability replacements in the more than 40-year old injector complex; emittance reduction measures in the injector chain; stochastic cooling in RHIC [1]; the extension of the energy range to higher [2] and lower values; an upgrade to the polarized source [3], a second cold snake in the AGS, a further reduction of the beam size at the interaction point, and the use of electron lenses and superbunches [4]. In this article we will not report on the planned electron-ion collider eRHIC. This is covered in a separate article [5]. 


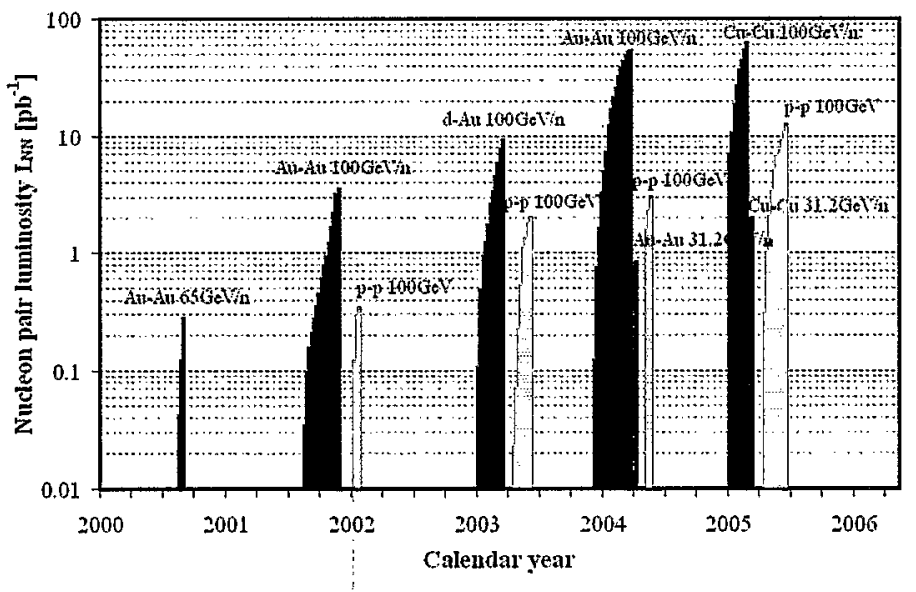

FIGURE 1. Integrated nucleon-pair luminosity delivered to PHENLX, one of the high-luminosity experiments at RHIC [6]. The integrated nucleon-pair luminosity is defined as $L_{N N}=\int A_{1} A_{2} \mathscr{L} d t$, where $\mathscr{L}$ is the luminosity, and $A_{1}$ and $A_{2}$ are the number of nucleons of the ions in the 2 beams respectively.

\section{ENHANCED LUMINOSITY AND POLARIZATION}

The enhanced design parameters call for an increase in the heavy ion luminosity by a factor 2 , and an increase in the polarized proton luminosity by an order of magnitude (Tab. 1). In addition, the average proton polarization in RHIC stores is to increase from $46 \%$ to $70 \%$. Those goals are expected to be reached in 2009 .

The intensity of all beams is limited by dynamic pressure rises, cause by electron clouds. In the warm sections, the beam pipes are replaced by NEG coated pipes, which have a lower Secondary Electron Yield, and act as a distributed pump when activated. In the cold section, additional pumps were installed to evacuate the beam pipe to a lower pressure before the cool-down of the magnets.

The proton polarization and bunch intensity is currently limited by the AGS, which is the injector for RHIC. It is expected that both limits can be overcome when a cold Siberian snake, installed in 2005 , is fully commissioned. The luminosity lifetime protons is dominated by the beam-beam interaction, and a number of improvements are planned to ameliorate the effect.

\section{ELECTRON BEAM ION SOURCE}

Currently only species for which high intensity negative ion sources exist can be used. These negative ions are accelerated in the electrostatic Tandem accelerator, and then injected into the AGS Booster. It is planned to replace the pair of Tandems with an Electron Beam Ion Source (EBIS) followed by a Radio Frequency Quadrupole (RFQ) and short Linac [7]. With the construction of EBIS a further upgrade of the Tandems can be avoided, needed to maintain their reliability, and new ion species can be prepared for RHIC, including uranium and polarized ${ }^{3} \mathrm{He}$. The overall system reliability is expected to be improved at reduced operating costs, with beam intensity and brightness comparable to the existing scheme. It is planned to commission EBIS in 2009. 
TABLE 1. Main RHIC parameters for gold ions and polarize protons.

\begin{tabular}{|c|c|c|c|c|c|}
\hline \multirow{2}{*}{$\frac{\text { Quantity }}{\mathbf{A u}^{79+} \text { on } \mathbf{A u}^{79+}}$} & \multirow[t]{2}{*}{ Unit } & $\begin{array}{c}\text { Design } \\
1999\end{array}$ & $\begin{array}{c}\text { Achieved } \\
2005\end{array}$ & $\begin{array}{c}\text { Enhance } \\
\text { Design } \\
2009\end{array}$ & $\underset{\geq 2012}{\text { RHIC II }}$ \\
\hline & & & & & \\
\hline Beam energy & $\mathrm{GeV} / \mathrm{n}$ & & & 100 & \\
\hline Number of bunches & (n) & 60 & 45 & & \\
\hline Bunch population, initial & $10^{9}$ & 1.0 & 1.1 & & \\
\hline$\beta$-function at IP & $\mathrm{m}$ & 2.0 & 1.0 & 1.0 & 0.5 \\
\hline Peak luminosity & $10^{26} \mathrm{~cm}^{-2} \mathrm{~s}^{-1}$ & 12 & 15 & 32 & 90 \\
\hline Average store luminosity & $10^{26} \mathrm{~cm}^{-2} \mathrm{~s}^{-1}$ & 2 & 5 & 8 & 70 \\
\hline polarized $\mathrm{p}^{+}$on polarize & & & & & \\
\hline Beam energy & $\mathrm{GeV}$ & 250 & 100 & & \\
\hline Number of bunches & $\ldots$ & 60 & 106 & & \\
\hline Bunch population, initial & $10^{11}$ & 1.0 & 0.9 & & \\
\hline$\beta$-function at IP & $\mathrm{m}$ & 2.0 & 1.0 & 1.0 & 0.5 \\
\hline Peak luminosity & $10^{30} \mathrm{~cm}^{-2} \mathrm{~s}^{-1}$ & 15 & 10 & 220 & 750 \\
\hline Average store luminosity & $10^{30} \mathrm{~cm}^{-2} \mathrm{~s}^{-1}$ & 10 & 7 & 150 & 500 \\
\hline Average store polarization & $\%$ & - & 46 & 70 & 70 \\
\hline
\end{tabular}

\section{ELECTRON COOLING - RHIC II}

The luminosity lifetime of heavy ions is dominated by intrabeam scattering effects. These lead to particle loss out of the radio frequency buckets, and to an increase in the beam size during stores. The effects of intrabeam scattering can only be overcome through active cooling. To cool heavy ion beams at store, an electron beam of $54 \mathrm{MeV}$ with an intensity comparable to the ion beam is required. Such an electron beam has a power of about a megawatt. A high intensity, high brightness superconducting if electron gun is being developed, which will injected into a superconducting energy recovery linac (ERL). To advance the technology, a R\&D ERL is being constructed, in which the electron beam will reach about half the energy required in the electron cooler. Technically constraint, electron cooling could be commissioned in RHIC in 2012.

\section{ACKNOWLEDGMENTS}

The authors are thankful to the members of Brookhaven's Collider-Accelerator Department, whose combined work is reported here. Work supported by U.S. DOE under contract No DE-AC02-98CH10886.

\section{REFERENCES}

1. J.M. Brennan and M. Blaskiewicz, COOL05, to be published as AIP conference proceedings (2005).

2. W.W. MacKay et al., proceedings of the 2001 Particle Accelerator Conference, pp. 3129-3131 (2001).

3. A. Zelenski, private communication (2005).

4. W. Fischer and M. Blaskiewicz, AIP Conference Proceedings 693, pp. $244-247$ (2003).

5. V. Ptitsyn, these proceedings; R. Fatemi, these proceedings.

6. W. Fischer, http://www.rhichome.bnl.gov/RHIC/Runs/ (2005).

7. J. Alessi et al., proceedings of the 2005 Particle Accelerator Conference, pp. 363-365 (2005).

8. I. Ben-Zvi et al., proceedings of the 2005 Particle Accelerator Conference, pp. 48-51 (2005). 